Vol. 1 | No. 3 | Juli 2020 | Hal. 239 - 245

\title{
PEMBERDAYAAN MASYARAKAT DESA MELALUI TEKNOLOGI PENGOLAHAN PUPUK ORGANIK
}

\author{
Oktavia Rahayu Puspitarini, Alif Brillian Abiwardhani, Shelly Eka Purnama, Nur Laili \\ Azizah, Ahmad Fadholi, Khoirul Fanani, Muhammad Mu'is, Nabila Latifa Hae, \\ Desirma Cipta Masnaly, Muhammad Rahul Khadafi, Rizki \\ Fakultas Peternakan, Universitas Islam Malang
}

Korespondensi email: oktaviarahayu@unisma.ac.id

\begin{abstract}
ABSTRAK
Limbah usaha peternakan dapat menimbulkan permasalahan lingkungan sekitar pemukiman dimana usaha peternakan berada, jika tidak dikelola dengan baik. Oleh karena itu muncullah inovasi baru, diantaranya pemanfaatan produk limbah kotoran agar menjadi produk yang memiliki nilai jual dan diharapkan mampu menjaga ketahanan ekonomi masyarakat sekitar dan limbah kotoran juga diharapkan mampu mengurangi pencemaran lingkungan yang terjadi. Tujuan pengabdian ini adalah memberdayakan masyarakat desa Kidal Kecamatan Tumpang, Desa Banjararum Kecamatan Singosari Kabupaten Malang melalui teknologi pengolahan pengolahan pupuk organik. Kegiatan ini menggunakan metode pendekatan yaitu tahap pertama observasi kondisi awal potensi peternakan yang dihadapi oleh masyarakat mengenai limbah. Tahap kedua adalah perencanaan untuk memecahkan masalah berupa kegiatan sosialisasi dan pelatihan pembuatan produk secara langsung. Tahap ketiga adalah sosialisasi dan pelatihan pembuatan pupuk organik. Tahap terakhir evaluasi program. Hasil kegiatan sosialisasi dan pelatihan pembuatan produk adalah meningkatkan pengetahuan kepada para peternak bahwa limbah dapat dimanfaatkan sebagai pupuk organik kompos sehingga timbulnya kesadaran petani dan peternak untuk memulai dan mengembangkan kebiasaan memberikan pupuk kompos organik yang baik bagi tanaman serta peternak dapat membuat pupuk organik secara mandiri dengan menggunakan bantuan bakteri em-4 yang berfungsi sebagai aktivator kompos melalui proses fermentasi. Kesimpulannya adalah masyarakat desa memahami adanya potensi olahan limbah menjadi produk pupuk organik. Dengan adanya inovasi tersebut membantu perekonomian masyarakat dan mengurangi dampak limbah peternakan serta mengurangi ketergantungan penggunaan pupuk kimia di Desa Kidal Kecamatan Tumpang, Desa Banjararum Kecamatan Singosari Kabupaten Malang.
\end{abstract}

Kata Kunci: pemberdayaan masyarakat; pupuk organik; limbah peternakan.

\section{PENDAHULUAN}

Masa pandemi Covid-19 saat ini mengakibatkan munculnya masalah baru di masyarakat secara global, terutama dalam segi ekonomi. Masyarakat diharuskan menerapkan protokol kesehatan (social distancing) dalam menjalani kegiatan sehari-hari di era new normal (Jureid, 2020). Bekerja dengan kondisi tersebut menjadi tantangan tersendiri bagi masyarakat dalam memenuhi kebutuhan yang diperlukan, akhirnya masyarakat berusaha memanfaatkan limbah peternakan untuk tetap dimanfaatkan menjadi produk yang bernilai jual dan dapat digunakan. Limbah erat kaitannya dengan 
pencemaran, karena limbah inilah yang menjadi substansi pencemaran lingkungan, karena itu, pengolahan limbah sangat dibutuhkan agar tidak mencemari lingkungan (Pitoyo, Arthana, \& Sudarma, 2016; Yunik'ati, Imam, Hariyadi, \& Choirotin, 2019).

Pengolahan limbah kotoran ayam ternak dilakukan di Desa Kidal Kecamatan tumpang Kabupaten malang, lokasi yang berada di lereng pegunungan tengger ini merupakan sentra penyalur produksi telur di kota malang yang mayoritas masyarakatnya sebagai peternak ayam layer. Jumlah peternak di Kidal kurang lebih 200 peternak, yang masing-masing peternak mengelola sekitar 10.000 ekor ayam layer. Dampak yang dirasakan oleh masyarakat sekitar yaitu, terganggu dengan adanya penumpukan kotoran ayam yang mengundang lalat serta penyakit dan timbulnya bau tidak sedap. Bau tersebut berasal dari kandungan gas amonia yang tinggi dan gas hidrogen sulfida, $\left(\mathrm{H}_{2} \mathrm{~S}\right)$, dimetil sulfida, karbon disulfida, dan merkaptan. Senyawa yang menimbulkan bau ini dapat mudah terbentuk dalam kondisi anaerob seperti tumpukan kotoran yang masih basah (Rachmawati, 2000; Noerhayati \& Lesmanah, 2018). Limbah organik akan meningkatkan kadar nitrogen menjadi senyawa nitrat yang menyebabkan bau busuk (Kurniawan, Purwanto, \& Sudarno, 2013; Rhofita \& Chana AW, 2019). Artinya dengan kondisi desa seperti ini pasti memiliki potensi untuk dimanfaatkannya limbah ternak yang sejatinya tidak digunakan oleh para peternak dan belum adanya pengolahan lebih lanjut. Maka dari itu tim kami memiliki inovasi untuk mengolah kotoran tersebut menjadi pupuk organik dengan pengolahan mudah dan memiliki nilai jual untuk membantu menyeimbangi kebutuhan perekonomian masyarakat sekitar.

Dengan memanfaatkan fermentasi dan bahan media seperti air, tetes gula, dan juga bakteri Em-4 yang dijadikan satu lalu ditambah kotoran ternak dan ditutup rapat maka akan terjadinya proses pembusukan secara anaerob. Bakteri Em-4 biasa menggunakan starter yang mana starter merupakan populasi mikroba dalam jumlah dan kondisi fisiologis yang siap diinokulasikan pada media fermentasi (Prabowo, AE, \& J, 2013). Fermentasi merupakan suatu proses perubahan kimia pada suatu substrat organik melalui aktivitas enzim yang dihasilkan oleh mikroorganisme (Wulandari, Sukanto, \& Widyastuti, 2014). Fermentasi akan membantu proses pembusukan kotoran ternak agar bisa diolah dan digunakan sebagai pupuk organik. Proses pembusukan terjadi secara anaerob selama 14 hari. Hasil dari fermentasi bahan organik yang dilakukan oleh mikroorganisme efektif (EM) adalah asam laktat, asam amino, yang dapat diserap langsung oleh tanaman sebagai antibiotik yang mampu menekan pertumbuhan mikroorganisme yang merugikan (Tufaila, Laksana, \& Alam, 2014).

Berdasarkan kondisi observasi di Desa Kidal Kecamatan Tumpang, Desa Banjararum Kecamatan Singosari Kabupaten Malang maka Tim KKN Tematik 42 Universitas Islam Malang 2020 memberikan sebuah inovasi pemberdayaan masyarakat melalui teknologi pupuk organik. Tujuan dari kegiatan ini adalah meningkatkan aktivitas masyarakat untuk memproduksi olahan limbah berupa pupuk organik secara mandiri, memanfaatkan limbah peternakan menjadi produk yang bernilai jual dan bermanfaat, membantu meringankan biaya kebutuhan pertanian dengan mengurangi penggunaan pupuk kimia serta mengurangi pencemaran lingkungan. Limbah peternakan sebagai sumber daya yang mempunyai nilai ekonomi dan dapat dimanfaatkan, misalnya untuk energi kompos, ataupun pupuk organik (Wibowo \& Andreani, 2013).

\section{METODE}

Metode pendekatan yang digunakan untuk menyelesaikan masalah di Desa Kidal Kecamatan Tumpang, Desa Banjararum Kecamatan Singosari Kabupaten Malang mengenai limbah sebagai berikut: 
1. Tahap pertama adalah program ini diawali dengan melakukan observasi terhadap kondisi awal potensi peternakan di Desa Kidal Kecamatan Tumpang, Desa Banjararum Kecamatan Singosari Kabupaten Malang. Kegiatan wawancara dan observasi ke lapangan oleh Tim KKN-PPM 42 UNISMA untuk mendapatkan data awal untuk referensi tindakan pengembangan dan perbaikan. Berangkat dari permasalahan yang dirumuskan, maka program kegiatan KKN-PPM yang akan dilaksanakan merupakan solusi terhadap masalah pandemi covid-19 yang dihadapi.

2. Tahap kedua adalah perijinan dan koordinasi kepada ketua RT setempat langsung untuk melakukan edukasi pemanfaatan limbah kepada para peternak, kemudian di teruskan lagi kepada pihak peternak setempat melalui pemberitahuan ketua RT, setelah adanya kesepakatan tim Tim KKN-PPM 42 UNISMA menyampaikan akan dilaksanakannya kegiatan edukasi, sosialisasi dan pelatihan langsung pembuatan produk pada hari Senin, 3 Agustus 2020 pukul 07.00 sampai selesai. Koordinasi.

3. Tahap ketiga adalah sosialisasi dan pelatihan pembuatan pupuk organik

Tahapan-tahapan pembuatan dan pelaksaan dalam membuat pupuk organik yaitu:

a. Proses pembuatan pupuk organik dengan menyiapkan bahan yang diperlukan terutama pada kotoran ternak sebagai media yang diambil menggunakan cangkul dan dihaluskan dengan cara mencacah menggunakan cangkul.

b. Pembuatan dan pecampuran bahan dengan yang diolah dengan proses pencampuran pada media air, yang diberi cairan Em-4 dan tetes tebu yang kemudian diaduk hingga tercampur.

c. Pencampuran media kotoran dengan bahan cairan dilakukan menggunakan alat Gembor air yang dituangkan pada media hingga merata yang dibantu perataannya menggunakan cangkul, dan ketika telah dicampur dilakukan proses penutupan media yang tercampur dengan terpal sampai kedap udara, karena dilakukan pembusukan secara anaerob.

d. Proses pengangkatan media yang telah jadi kemudian dibagikan kepada masyarakat di beberapa daerah terutama di desa Kidal Kecamatan Tumpang dan juga di Desa Banjararum Kecamatan Singosari Kabupaten Malang.

4. Tahap keempat adalah evaluasi program yang dilakukan dalam jangka waktu 14 hari, yang setiap harinya dicatat dan dimonitoring bagaimana hasil pencampuran bahan dan media tersebut, yang kemudian di recording setiap minggu apakah secara tekstur, aroma, dan kelembapan telah sesuai dengan prosedur. Dan setelah pemantauan secara berkala pupuk tersebut di tentukan apakah layak untuk dibagikan pada desa setempat. Untuk evaluasi sendiri dilakukan oleh seluruh anggota tim kami.

\section{HASIL DAN PEMBAHASAN}

Pembuatan pupuk organik dengan memanfaatkan kotoran ternak dilaksanakan pada hari Senin Tanggal 3 Agustus 2020 yang bertempat di rumah saudara Khoirul fanani di desa Kidal Kecamatan Tumpang Kabupaten Malang. Pembagian pupuk dilaksanakan pada 22 Agustus 2020 yang dibagikan di beberapa lokasi terutama di Desa Kidal Kecamatan Tumpang, Desa Banjararum Kecamatan Singosari Kabupaten Malang. Diharapkan dengan adanya solusi yang ditawarkan TIM KKN 42 UNISMA ini dapat mengatasi permasalahan masyarakat dalam menghadapi pandemi covid-19 ini dengan memanfaatkan limbah ternak sebagai pupuk organik dan pengganti pupuk kimia sebagai kebutuhan nutrisi pada sektor pertanian dimasyarakat. Kegiatan KKN yang utama adalah yang berkaitan mencari solusi terhadap kendala kendala yang dihadapi masyarakat terkait masalah ekonomi (Sekarsari et al., 2020). 
Hasil observasi di desa Kidal Kecamatan Tumpang Kabupaten Malang membuat kami berinovasi dalam pembuatan pupuk organik dari limbah peternakan yang dibuang tanpa adanya pengolahan kembali, guna membantu menaikkan harga jual dan kreativitas dari masyarakat dalam mengolah limbah peternakan. Hasil kegiatan yang kami lakukan, yaitu:

1. Berdasarkan hasil survey dan hasil wawancara kepada RT setempat ditemukan permasalahan berupa limbah kotoran ayam yang menumpuk dan tidak dilakukannya pengolahan kembali serta mencemari lingkungan warga sehingga dikhawatirkan mengganggu kesehatan warga sekitar.

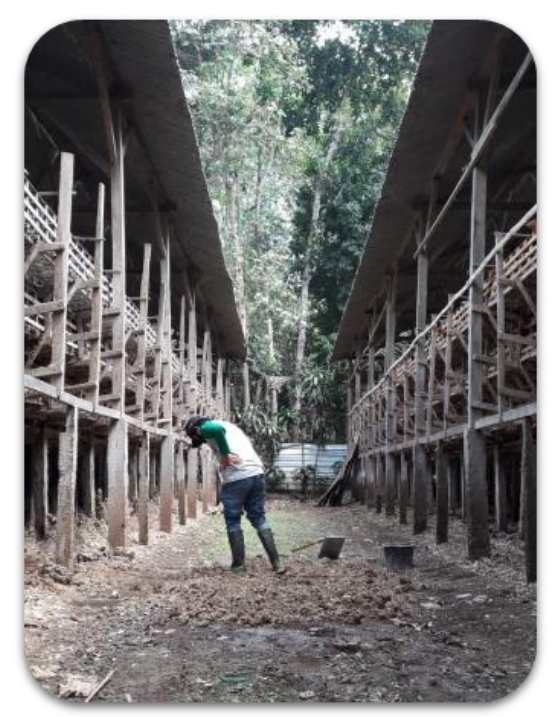

Gambar 1. Survey lapangan (dok. KKN Kel. 42)

2. Setelah menemukan permasalahan yang terjadi dimasyarakat kami merencanakan kegiatan berupa sosialisasi dan pelatihan langsung pembuatan pupuk kompos menggunakan limbah kotoran ayam layer. Hasil dari kegiatan koordinasi ini adalah mitra menyetujui program yang direncanakan oleh tim KKN 42 UNISMA. Hal ini penting untuk dilakukan untuk menyepakati program kerja yang akan dilaksanakan dalam KKN.

3. Tahap selanjutnya, adalah kegiatan sosialisasi dan pelatihan pembuatan pupuk ini tim KKN memberikan bakteri EM4 yang berguna untuk aktivator kompos. Setelah pencampuran semua bahan pupuk organik di tutup rapat dengan terpal agar terjadi proses pembusukan (fermentasi) secara anaerob. Pembuatan kompos yang sangat mudah dengan bahan yang murah serta mudah ditemukan dan peternak pun gampang untuk mengikutinya.

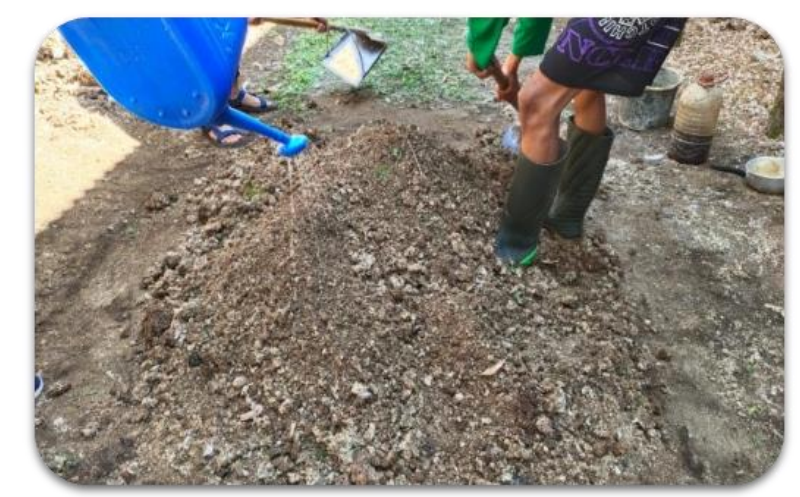

Gambar 2. Penambahan air pada pupuk organik (dok. KKN Kel. 42) 


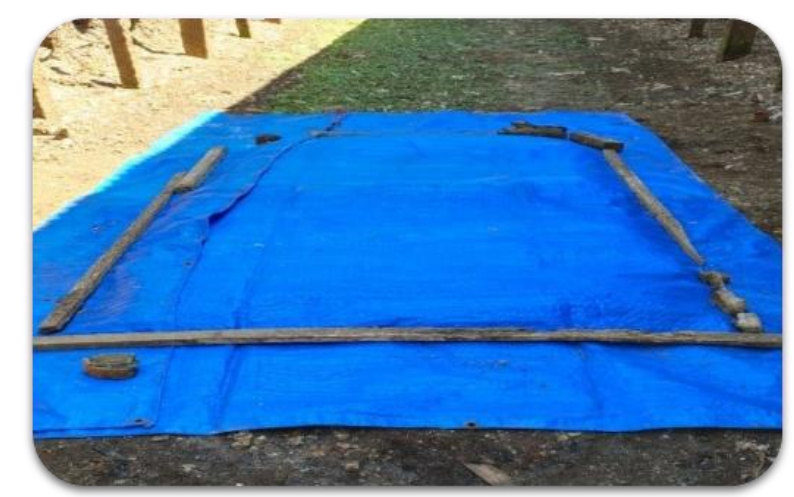

Gambar 3. Proses Fermentasi (dok. KKN Kel. 42)

4. Terakhir evaluasi dilakukan selama 14 hari, dan dilakukan pengecekan tekstur, aroma, dan kelembapan telah sesuai dengan prosedur. Evaluasi merupakan kelanjutan dari suatu rencana kerja yang peranannya sangat di butuhkan karena evaluasi merupakan latihan yang memperkaya logika dan juga analisa (Gede, 2015). Dengan adanya evaluasi ini dapat membantu program yang dikerjakan dapat terarah dengan benar dan dengan adanya evaluasi pupuk yang dihasilkan pun sesuai dengan prosedur pembuatannya tidak ada kekurangan ataupun kesalahan saat pembuatan selanjutnya. Setelah dilakukan nya pembuatan pupuk dan siap untuk di gunakan maka kami langsung dibagikan ke beberapa tempat wilayah malang agar membuat para peternak dan petani tetap memperhatikan lahan pertanian bagi tanaman.

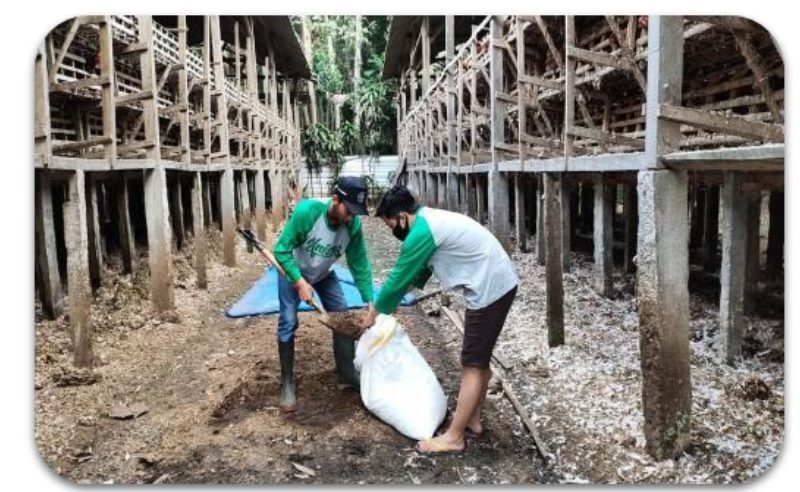

Gambar 4. Proses memasukkan pupuk ke karung (dok. KKN Kel. 42)

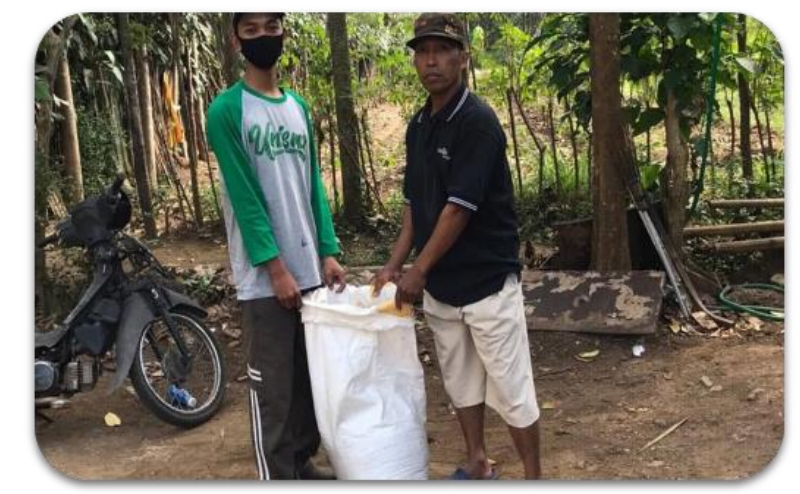

Gambar 5. Pembagian pupuk organik (dok. KKN Kel. 42)

Masyarakat sangat diuntungkan dengan adanya inovasi pembuat pupuk dan pembagian pupuk dari Tim KKN 42 Unisma ini karena selain membantu petani untuk 
mengurangi pupuk kimia yang diberikan di lahan pertanian dan beralih ke pupuk kompos yang dapat menjadikan tanah subur dan hasil pertanian yang baik peternak juga mendapatkan keuntungan dari hasil penjualan pupuk organik ini. Hal ini selaras dengan hasil penelitian Chen \& Jiang (2014) serasah ayam atau pupuk organik berbasis sampah ayam dapat didaur ulang menjadi media untuk memperbaiki struktur dan kesuburan lahan pertanian. Rachid dkk. (2014) juga menunjukkan bahwa penerapan pupuk kandang ayam memperbaiki beberapa sifat tanah, menyebabkan peningkatan yang signifikan dalam tanah konduktivitas listrik (EC), kandungan fosfor dan nitrat (NO3-).

\section{KESIMPULAN}

Berdasarkan hasil kegiatan, dapat disimpullkan bahwa masyarakat desa memahami adanya potensi olahan limbah menjadi produk pupuk organik. Dengan adanya inovasi tersebut membantu perekonomian masyarakat dan mengurangi dampak limbah peternakan serta mengurangi ketergantungan penggunaan pupuk kimia di Desa Kidal Kecamatan Tumpang, Desa Banjararum Kecamatan Singosari Kabupaten Malang.

\section{DAFTAR RUJUKAN}

Chen, Z., \& Jiang, X. (2014). Microbiological Safety of Chicken Litter or Chicken Litter-Based Organic Fertilizers: A Review. Agriculture, 4(1), 1-29. https://doi.org/10.3390/agriculture4010001

Jureid. (2020). Ekonomi Syariah Sebagai Alternatif Kesejahteraan Ekonomi Masyarakat Pada Era Covid-19. Jurnal Kajian Ekonomi Dan Kebijakan Publik, 5(2), 224-236. Retrieved from http://jurnal.pancabudi.ac.id/index.php/jepa/article/view/910

Kurniawan, M. W., Purwanto, P., \& Sudarno, S. (2013). Strategi Pengelolaan Air Limbah Sentra UMKM Batik Yang Berkelanjutan Di Kabupaten Sukoharjo. Jurnal Ilmu Lingkungan, 11(2), 62-72. https://doi.org/10.14710/jil.11.2.62-72

Noerhayati, E., \& Lesmanah, U. (2018). IbM Pemanfaatan Limbah Ternak Kelompok Tani Kedung Sumber Kab. Bojonegoro. Jurnal Inovasi Hasil Pengabdian Masyarakat (JIPEMAS), 1(2), 149-151. https://doi.org/10.33474/jipemas.v1i2.1520

Pitoyo, P. N. P., Arthana, I. W., \& Sudarma, I. M. (2016). Kinerja Pengelolaan Limbah Hotel Peserta Proper Dan Non Proper Di Kabupaten Badung, Provinsi Bali. ECOTROPHIC: Jurnal Ilmu Lingkungan (Journal of Environmental Science), 10(1), 33. https://doi.org/10.24843/ejes.2016.v10.i01.p06

Prabowo, A., AE, S., \& J, K. (2013). Pengaruh Penambahan Bakteri Asam Laktat Terhadap Ph Dan Penampilan Fisik Silase Jerami Kacang Tanah. In Seminar Nasional Teknologi Peternakan dan Veteriner (pp. 495-499). Medan: Badan Penelitian dan Pengembangan Pertanian. Retrieved from https://docplayer.info/30371502Pengaruh-penambahan-bakteri-asam-laktat-terhadap-ph-dan-penampilan-fisiksilase-jerami-kacang-tanah.html

Rachmawati, S. (2000). Upaya pengelolaan lingkungan usaha peternakan ayam. Wartazoa, 9(2), 73-80.

Rhofita, E. I., \& Chana AW, L. (2019). Pemanfaatan Limbah Jerami Padi Di Desa Garon Kecamatan Balerejo, Kabupaten Madiun. Jurnal Inovasi Hasil Pengabdian Masyarakat (JIPEMAS), 2(2), 120-131. https://doi.org/10.33474/jipemas.v2i2.2915

Sekarsari, R. W., Fabiola, J. D., Hidayatullah, R., Oktaviana, D., Ma'arif, S. D., Riansyah, I. A. S., ... Sahroni, A. (2020). Meningkatkan Potensi Sumber Daya Alam Untuk Mewujudkan Desa Wisata. Jurnal Pembelajaran Pemberdayaan Masyarakat (JP2M), 1(2), 153-160. https://doi.org/10.33474/jp2m.v1i2.6509

Tufaila, M., Laksana, D. D., \& Alam, S. (2014). APLIKASI KOMPOS KOTORAN AYAM UNTUK 
MENINGKATKAN HASIL TANAMAN MENTIMUN ( Cucumis sativus L .) DI TANAH MASAM Application of Chicken Manure Compost to Improve Yield of Cucumber Plant ( Cucumis sativus L .) In Acid Soils. Agroteknos, 4(2), 120-127. Retrieved from http://ojs.uho.ac.id/index.php/agroteknos/article/view/216

Wibowo, M., \& Andreani, F. (2013). Analisis Penerapan Sistem Manajemen Limbah Berdasarkan Sertifikasi Eco-Hotel Di Sheraton Surabaya Hotel and Towers. Jurnal Hospitality Dan Manajemen Jasa, 1(2), 389-401. Retrieved from http://publication.petra.ac.id/index.php/manajemenperhotelan/article/view/1000

Wulandari, N., Sukanto, S., \& Widyastuti, E. (2014). Pengaruh Pemberian Mikroba Efektif Produktif Plus (Mep+) Pada Medium Budidaya Ikan Nila Yang Diberi Pakan Fermentatif Terhadap Kepadatan Bakteri Asam Laktat. Scripta Biologica, 1(1), 6165. https://doi.org/10.20884/1.sb.2014.1.1.27

Yunik'ati, Y., Imam, R. M., Hariyadi, F., \& Choirotin, I. (2019). Sadar Pilah Sampah Dengan Konsep 4R (Reduce, Reuse, Recycle, Replace) Di Desa Gedongarum, Kanor, Bojonegoro. Jurnal Inovasi Hasil Pengabdian Masyarakat (JIPEMAS), 2(2), 81-87. https://doi.org/10.33474/jipemas.v2i2.1122 